\title{
Water Reuse Planning for Fulfilment of Clean Water in Indonesia
}

\author{
Wedo Aru Yudhantoro ${ }^{1 *}$, Suyud Warno Utomo², Dwi Nowo Martono ${ }^{2}$ \\ ${ }^{1}$ Magister Program of Environmental Science, School of Environmental Science \\ Universitas Indonesia \\ ${ }^{2}$ School of Environmental Science, Universitas Indonesia
}

\begin{abstract}
The number of clean water needed will always increase when the number of the population still shows growth. It must have the same level from the supply and demand or the supply of clean water has higher than the demand for clean water. Some cities in Indonesia have problems with the fulfilment of clean water. Factors from climate change, behaviour, and management can affect the conditions of clean water resources. The development of technologies and science makes the reuse of the water process can be done for another resource of clean water fulfilment. Rainwater harvesting, membrane bioreactors, reverse osmosis, and filtration systems are some kind of processing systems for the water mechanism for the fulfilment of clean water. Sustainable clean water resources and supply is one of the indicators of sustainable development goals. This research was conducted to see how is the potential of water reuse for the fulfilment of clean water in Indonesia by using several systems or processing that have been installed and used. The control and evaluation is the best key to make sure the clean water resources still in the best condition and water reuse is one of the plan to support fulfilment of clean water.
\end{abstract}

\section{Introduction}

The trends in population growth globally have shown increases in several years. The population growth in technology can affect the number of clean water needed. Limited natural resources can make some problems when the demanded number of clean water is higher than the supply. The deficit of clean water numbers can create some problems such as disturbed of clean water distribution, limited access to water for all peoples, poor environmental quality, and social conflict [1]. The deficit of water resource problems already happened in urban areas [2]. Based on several problems of water deficit, the development of technologies and science make the water reuse process is possible to do for the fulfilment of clean water [3-4].

\footnotetext{
${ }^{*}$ Corresponding author: wedo.aru@ui.ac.id
} 
Water reuse was developed as an emerging condition to create new resources for the fulfilment of water resources [5]. Kind of water reuse mechanisms are many and it depends on the water condition that needed of the system. Some alternate of the water reuse process has already installed and got some updated in some research process. Membrane systems, membrane bioreactors, rainwater harvesting, and desalination are some mechanisms to processing water reuse concept to the production of clean water [6-7]. That mechanism wasn't used all in someplace. It considers by looking at the condition of the cities such as water resources, the availability of technologies, the ability of the economics, and the problems of water resources needed. The fact, the number of water resources was got some competition between cities needed and agriculture needed [8]. The complexity of any sector that needed clean water resources makes all of the sectors that have importance on the fulfilment of water resources was needed the role to make sure the alternate from water reuse process has the best value to increase the supply of clean water. The role of government policy, people's behaviour from water using, until the ability of technologies and science had to the best part for the sustainability of water resources.

\section{Methodology}

This research was progress by a literature study process about water reuse potential for the fulfilment of clean water resources that comparing on a global scale and in Indonesia condition. This research will able to see how far the effects of water reuse mechanism for fulfilment in clean water needed from any activities and sectors. The data that attached in this research came from previous research. The data source used is research from the last ten years that can get some updated from the next of research from the same theme or keywords.

\section{Results and Discussion}

The number of water reuse processes in several countries has already increased significantly. It's because of the trend of population growth that the effect of water needed in any sectors that have already used water resources before. Agriculture, industry, and urban areas have already used water for their activities. Water reuse mechanism was being an alternative way for water needed. Water reuse in agriculture sector was used in irrigation process [9]. Some sectors from industry activities such as milk processing plant industry, steel industry, and urban activities already started to used water reuse in their activities in their production or waste management process $[10,11,12]$. The water reuse process have to consider in three aspects such as the environment quality, the values of economic, and acceptance in society [13]. That was needed to see all the processes from any aspect and what is the value that will get from the water reuse process for the fulfilment of clean water. From research of Wilcox et al 2016 [12] it has a triple bottom line assessment of urban water reuse. 


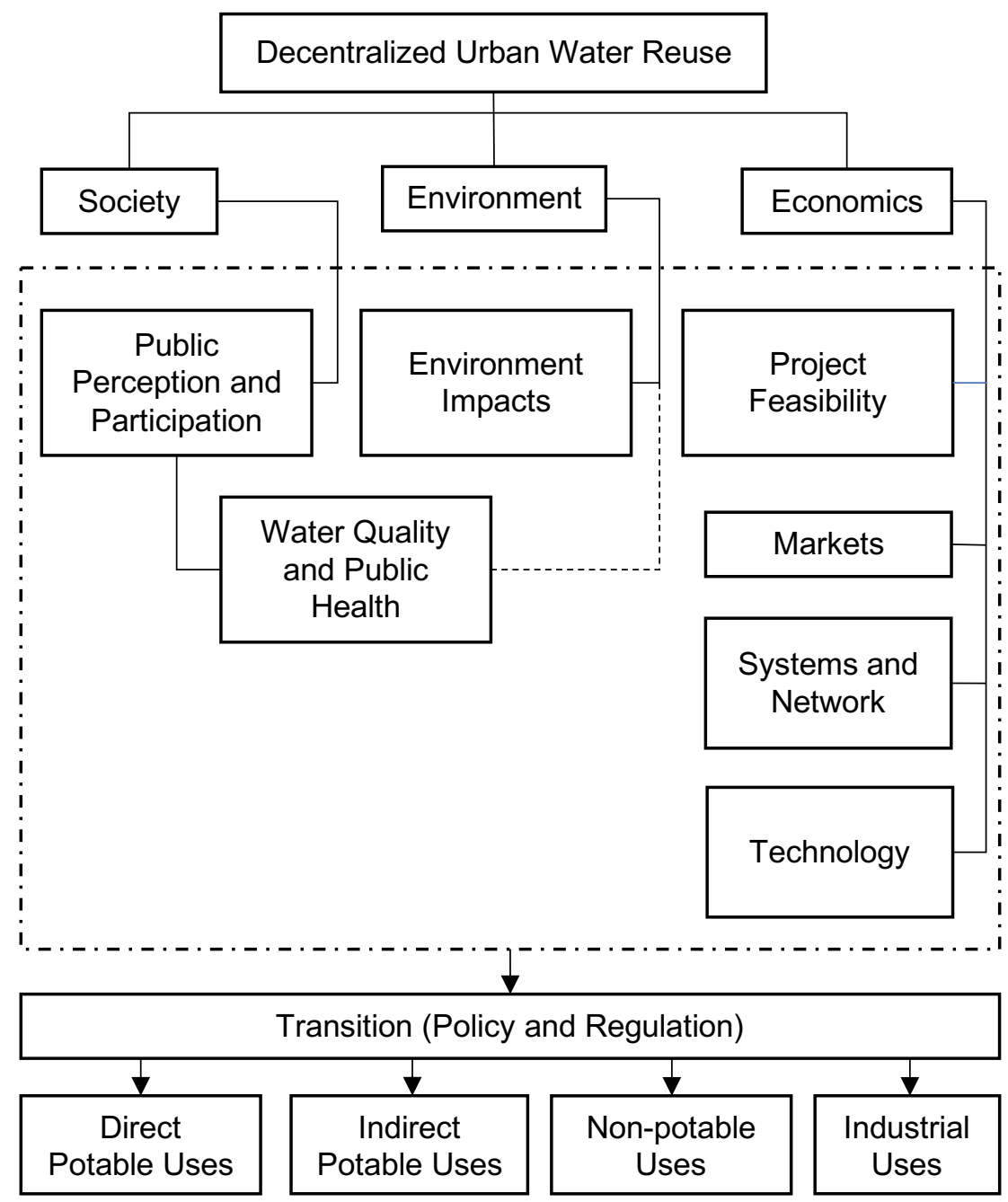

Fig. 1. Triple Bottom Assessment Concept for Urban Water Reuse [12].

Processing of water reuse mechanism has already increasingly significant because of the role of policy that needed some alternative for the fulfilment of clean water and evolution from technologies and science. It makes and gives some options for the water reuse process that can be installed and built as needed from the cases. Membrane bioreactors (MBR) is defined as a mechanical system that consists from some any part such as backwash pumps, effluent pumps, timer, pressure gauges, membrane modules, feeding tanks, and some the others [14]. Basically this mechanism was doing some filtration from any molecules or particle that needed to clean up and make the water in better quality. The MBR process was has a better value in efficiency of sludge process and get better value for money for the long time installation but at the first built it costing more higher than the conventional water treatment process [15-16]. Using of MBR mechanism can combining with another mechanism that depends on the condition of the water that will treatment in MBR such as palm oil wastewater using MBR combining with baffled air flotation or biofouling reducer or domestic wastewater using MBR combining with membrane fouling [17, 18, 19]. From the mechanism that doing in the water filtration process, it should consider the challenges 
from the applicated of the MBR system for water reuse [20]. The complexity of water that process will need more effort to get the best value or condition for water reuse.
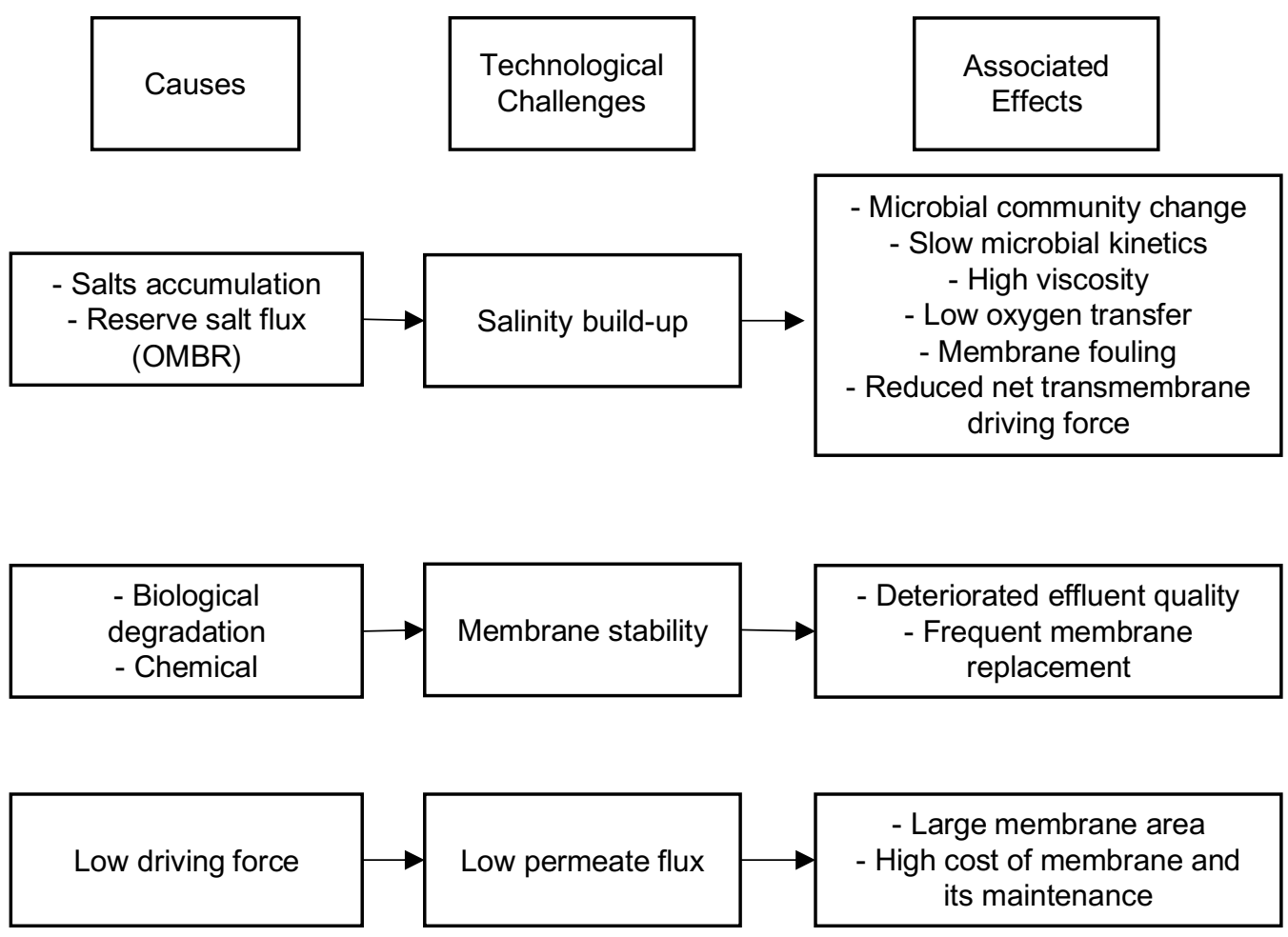

Fig. 2. Technology challenges of MBR Development [20].

Rainwater harvesting was one of the kind or mechanism of sustainable water management [21]. The mechanism of rainwater harvesting basically was to utilize rainwater and accommodate it on a tank that flowed by using pipe or something. For the best quality of water supply that gets from rainwater, it can be modified by our needed or the condition of the rainwater. The simple components concept is from rainfall, catchment area, filter, storage tank, and become water supply [22]. This mechanism just working when the rain is happening and it's depend on the condition of climate. This mechanism can be installed on any scale such as home scale, building scale, or some reservoir. Concept of rainwater harvesting has many applicated in Indonesia such is in household scale and recharge wells [23, 24]. Rainwater harvesting mechanism can replace some of the clean water needed that sources from natural water resources to before. This mechanism can effectively work on a place that has a higher rain intensity. The process of using rainwater harvesting must consider some impact to the ecology system. The reuse of water from rainwater harvesting in the householdscale can save up to $36 \%$ of the potable water demand [25]. It has a significant impact when all the household scales can or installed the rainwater harvesting system.

Reverse osmosis (RO) is defined as a system widely used in desalination technology. The system of RO has the best technology for the desalination process [26]. About $40 \%$ of the population around the world doesn't have access to sanitation or clean water resources. This gap made the RO mechanism has developed better to make the desalination process has the best quality. Technically, reverse osmosis plants weren't used for the desalination system only. It's already used in some applications such as food processing, power generation, biotechnology, textile, pulp and paper, mining, and some wastewater treatment [27]. The 
mechanism of RO is already used in the steel industry because the steel industry is one of the largest sectors for water-intensive industries. Water in the steel industry is used for some activities such as cooling activities process, gas cleaning, and sanitary applications process [11]. Reverse osmosis mechanism in the desalination process can be used to produce various water sources such as drinking water until demineralized water [28]. This depends on water sources that will process and it will need a different cost for the process. Reverse osmosis mechanism can combine with membrane bioreactors on wastewater or water filtration process which all the water filtration process can do some combination based on the water condition that will be processed [29].

Water reuse was known as an effective process and approach for doing some simultaneous of water scarcity problems and the environment quality from some pollutant [30]. The concept of water reuse can support of water conservation for the sustainable goals. It's can be a simple solution for the complex problem of water fulfilment and water quality [31]. The water reuse process in Indonesia still not as much when we talk on a global scale. But it's already growing and needed some increase by the role of technology, science, and the policy. Indonesia was a country that has bigger water reserves in the world. But from all the water potential, it's only $17 \%$ of the water potential can usable [32]. From this condition, water reuse management and process were needed for the fulfilment of clean water in Indonesia. The water reuse mechanism has needed to be provided in environmental quality, the social impact, and the values for economic. These things can affect investing or installing of water reuse mechanism but needed to consider the water condition that will process. The water reuse process was support to water conservation and make some activity that needed water would not depend on natural water resources.

The trend of water reuse on a global scale has already increased. In the next future, water reuse will be predicted to have more number than the desalination process for the fulfilment of clean water [33]. There are some multi-criteria that needed for the water reuse selection process based on three aspects, environment quality, economics, and social. Some indicators such as energy use indicators, carbon emissions, freshwater saving, life cycle cost, government policy, human health risk, and public acceptability are some of the things that considered on the water reuse selection process [33]. The trend of water reuse in Indonesia still grows. Some mechanism like rainwater harvesting has already increasing higher on a place that has a low rainfall scale and has a long dry season [34]. But some mechanisms such as membrane bioreactors and reverse osmosis needed more significant research and application for process in water for the fulfilment of clean water.

\section{Conclusion}

The water reuse mechanism already has a significant role in the fulfilment of clean water. Reverse osmosis, rainwater harvesting, and membrane bioreactors are the example of mechanism system to get an alternative water resource. The aspect of the environment, economics, and social must be a consideration to make sure all the processes will get the best values when we compared it with the last mechanism. Technologies and science growth has a bigger role in the quality of water reuse for this time. The things that give some effect to the quality of water reuse must be needed to improving such as the wise behaviour to use the clean water, management quality of the process, monitoring and control of the process, and the ability to create more water reuse systems on a big scale. 


\section{References}

[1] Aziz F and Farissi M., Reuse of Treated Wastewater in Agriculture: Solving Water Deficit Problems in Arid Areas (Review), XVII 95-110 (2014)

[2] Chen Z, Wu Q, Wu G and Hu H Y. Centralized water reuse system with multiple applications in urban areas: Lessons from China's experience Resour. Conserv. Recycl. 117 125-36 (2017)

[3] Kiparsky M, Sedlak D L, Thompson B H and Truffer B. The innovation deficit in urban water: The need for an integrated perspective on institutions, organizations, and technology. Environ. Eng. Sci. 30 395-408 (2013)

[4] Navarro T. Water reuse and desalination in Spain - Challenges and opportunities. J. Water Reuse Desalin. 8 153-68 (2018)

[5] Molinos-Senante M, Hernández-Sancho F and Sala-Garrido R. Cost-benefit analysis of water-reuse projects for environmental purposes: A case study for spanish wastewater treatment plants. J. Environ. Manage. 92 3091-7 (2011)

[6] Gude V G. Desalination and water reuse to address global water scarcity. Rev. Environ. Sci. Biotechnol. 16 591-609 (2017)

[7] Bagheri M and Mirbagheri S A. Critical review of fouling mitigation strategies in membrane bioreactors treating water and wastewater. Bioresour. Technol. 258318 34 (2018)

[8] Flörke M, Schneider C and McDonald R I. Water competition between cities and agriculture driven by climate change and urban growth. Nat. Sustain. 151-8 (2018)

[9] Carr G, Potter R B and Nortcliff S. Water reuse for irrigation in Jordan: Perceptions of water quality among farmers. Agric. Water Manag. 98 847-54 (2011)

[10] Buabeng-Baidoo E, Mafukidze N, Pal J, Tiwari S, Srinivasan B, Majozi T and Srinivasan R. Study of water reuse opportunities in a large-scale milk processing plant through process integration. Chem. Eng. Res. Des. 121 81-91 (2017)

[11] Colla V, Branca T A, Rosito F, Lucca C, Vivas B P and Delmiro V M. Sustainable Reverse Osmosis application for wastewater treatment in the steel industry. J. Clean. Prod. 130 103-15 (2016)

[12] Wilcox J, Nasiri F, Bell S and Rahaman M S. Urban water reuse: A triple bottom line assessment framework and review. Sustain. Cities Soc. 27 448-56 (2016)

[13] Wirawan S M S, Maarif M S and Riani E. An evaluation of the sustainability of domestic wastewater management in DKI Jakarta, 10 147-60 (2018)

[14] Bagheri M, Mirbagheri S A, Kamarkhani A M and Bagheri Z. Modeling of effluent quality parameters in a submerged membrane bioreactor with simultaneous upward and downward aeration treating municipal wastewater using hybrid models. Desalin. Water Treat. 57 8068-89 (2016)

[15] Lin H, Chen J, Wang F, Ding L and Hong H. Feasibility evaluation of submerged anaerobic membrane bioreactor for municipal secondary wastewater treatment . Desalination 280 120-6 (2011)

[16] Khan M A, Ngo H H, Guo W, Liu Y, Chang S W, Nguyen D D, Nghiem L D and Liang H. Can membrane bioreactor be a smart option for water treatment? Bioresour. Technol. Reports 4 80-7 (2018)

[17] Faisal M, Machdar I, Gani A and Daimon H. The combination of air flotation and a membrane bioreactor for the treatment of palm oil mill effluent. Int. J. Technol. 7 767-77 (2016) 
[18] Damayanti A, Ujang Z and Salim M R. The influenced of PAC, zeolite, and Moringa oleifera as biofouling reducer (BFR) on hybrid membrane bioreactor of palm oil mill effluent (POME). Bioresour. Technol. 102 4341-6 (2011)

[19] Kerstens S M, Leusbrock I and Zeeman G. Feasibility analysis of wastewater and solid waste systems for application in Indonesia Sci. Total Environ. 530-531 53-65 (2015)

[20] Luo W, Hai F I, Price W E, Guo W, Ngo H H, Yamamoto K and Nghiem L D. High retention membrane bioreactors: Challenges and opportunities. Bioresour. Technol. $167539-46$ (2014)

[21] Ward S, Memon F A and Butler D. Performance of a large building rainwater harvesting system. Water Res. 46 5127-34 (2012)

[22] Mun J S and Han M Y. Design and operational parameters of a rooftop rainwater harvesting system: Definition, sensitivity and verification. J. Environ. Manage. 93 147-53 (2012)

[23] Susilo G E. Experience in Rainwater Harvesting Application at Household Scale in Bandar Lampung , Indonesia 5-7 (2015)

[24] Sudiajeng L, Wiraga I W, Parwita I G L and Santosa G. Domestic recharge wells for rainwater-harvesting in Denpasar City, Bali - Indonesia. Int. J. GEOMATE 13 50-7 (2017)

[25] Jenkins G A, Greenway M and Polson C. The impact of water reuse on the hydrology and ecology of a constructed stormwater wetland and its catchment. Ecol. Eng. 47 308-15 (2012)

[26] Arifin B, Achsani N A, Martianto D, Sari L K and Firdaus A H. Modeling the Future of Indonesian Food Consumption: Final Report 67 pp (2018)

[27] Malaeb L and Ayoub G M. Reverse osmosis technology for water treatment: State of the art review. Desalination 267 1-8 (2011)

[28] Wenten I G and Khoiruddin. Reverse osmosis applications: Prospect and challenges Desalination 391 112-25 (2016)

[29] Luo W, Phan H V., Xie M, Hai F I, Price W E, Elimelech M and Nghiem L D. Osmotic versus conventional membrane bioreactors integrated with reverse osmosis for water reuse: Biological stability, membrane fouling, and contaminant removal Water Res. 109 122-34 (2017)

[30] Luo W, Hai F I, Price W E, Elimelech M and Nghiem L D. Evaluating ionic organic draw solutes in osmotic membrane bioreactors for water reuse. J. Memb. Sci. 514 636-45 (2016)

[31] Qaiser K, Ahmad S, Johnson W and Batista J R. Evaluating water conservation and reuse policies using a dynamic water balance model. Environ. Manage. 51 449-58 (2013)

[32] Priadi C R, Suleeman E, Darmajanti L, Novriaty S, Suwartha N, Resnawati R, Handayani R, Putri G L, Felaza E and Tjahjono T. Water recycling opportunity in the business sectors of Greater Jakarta, Indonesia. Int. J. Technol. 8 1031-9 (2017)

[33] Chhipi-Shrestha G, Rodriguez M and Sadiq R. Selection of sustainable municipal water reuse applications by multi-stakeholders using game theory. Sci. Total Environ. $6502512-26$ (2019)

[34] Messakh J J, Moy D L, Mojo D and Maliti Y. The linkage between household water consumption and rainfall in the semi-arid region of East Nusa Tenggara, Indonesia IOP Conf. Ser. Earth Environ. Sci. 106 (2018) 